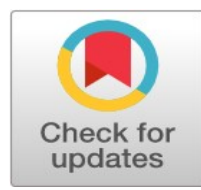

\title{
Study of access to health services of the elderly in Tambon Ban Khetmuang district health promotion hospital, Tambon Lat Yai, Samut Songkhram province
}

\author{
Veena Chantarasompoch ${ }^{1 *}$, Tipvarin Benjanirat ${ }^{2}$, Songchat Tosayanond ${ }^{3}$, \\ Chattraporn Prapasirisin ${ }^{4}$
}

1, 2, 3, 4 Suan Sunandha Rajabhat University, Bangkok, Thailand

\section{Key Words:}

Accessibility of health services Elderly

District health promotion hospital

Received: 23 August 2017 Accepted: 21 September 2017

Published: 16 October 2017

\begin{abstract}
This research aims to study on the accessibility of elderly to health services in district health promotion hospital, specifically in Lad Yai district, Samut Songkhram for the development of healthcare's procedure. The data gathering method is interviewing, which is from 72 samples that accessed in local health services in Lad Yai district, Samut Songkhram. The analytical method includes percentages, mean and standard deviation, which found that $73.6 \%$ are female, $29.2 \%$ are between $75-79$ years old, $48.6 \%$ are married, $63.9 \%$ are graduated at primary degree, and $66.7 \%$ are unemployed, and $65.0 \%$ have a lower salary than 5,000 baht. In addition, $18.1 \%, 16.7 \%$, and $9.7 \%$ have only hypertension, hypertension \& diabetes, and hypertension \& heart disease respectively. Furthermore, this research found that the opinions against the accessibility to overall healthcare at high levels $(\bar{X}=2.89, S . D=0.10)$, service location was appropriate lighting and personnel in highest levels $(\bar{X}=3.00, S . D=0.00)$, personnel found that understand the mean scores were at the highest level $(\bar{X}=3.00, S . D=0.00)$ whish was resulted from the staff said verbally polite, the staff expressions annoyed when asked, the staff was attentive and enthusiastic about the service, the staff willing to assist you, staff advised the relatives of elderly health care and description of the staff was easy to understand. Finally, the tools and equipment were given in highest levels $(\bar{X}=2.99$, S.D $=0.12$ ) which was resulted from the tools and equipment were up-to-date. while proper procedures also offer in highest levels $(\bar{X}=3.00, S . D=0.00)$.
\end{abstract}

\section{INTRODUCTION}

Foundation of Thai Gerontology Research and Development Institute (TGRI) announced the situation of the Thai Elderly in 2015 that, within 65.1 millions population, 11 millions or $16 \%$ of the population are over 60 years old and Thailand has become aging society since 2005 where $10 \%$ of population would become elderly which means that it would be $20 \%$ of elderly among the population in 2022 and at its peak of $28 \%$ in 2032 [1, 2, 3, 4]. In order to respond to The Twelfth National Economic and Social Development Plan (2017-2021), there are 6 key principles which are Sufficient Economy Philosophy, Human Centered Development, 20-year National Strategy framework (2017-2036) Sustainable Development Goals, Inequality Reduction Economic Growth, Knowledge Based Economy, and Practicality \& Long Term Achievements. Moreover, Human Centered Development

\footnotetext{
${ }^{*}$ Corresponding author: Veena Chantarasompoch

†Email: veena.ch@ssru.ac.th
} 
aims to increase the Thai's quality of life, developed them to be disciplined, skilled, knowledge, creative, and having good attitude, social responsibility in order to be prepared to getting into elderly society efficiently $[5,6,7]$.

The 2nd National Plan on Elderly (2002-2021) simulated the situation that affect operations. According to the plan, they found out that these elders would likely have a chronic disease and $20 \%$ of elders lack caretakers while $28.9 \%$ are taken care or able to access in local district health promotion hospital. In addition, only $1.9 \%$ of disabilities are taken care. As a result, those elders who would likely not receive the proper treatment are the most concerned group. Therefore, the development structure for the accessibilities and services of medical and public health is developed to increase the potential of healthcare services, disease control, treatment, and health recovery. In the end, diseases will turn into the aging degeneration, which is the reason why the need of services increase tremendously in elderly society $[8,9,10,11]$.

When the population of elders increase, social characteristics have to change and adapt to consider the existence and facilitate elders, especially healthcare. Other facilitations must also consider the accessing increment, which would face issues with healthcare allocations, tools, and equipment. Moreover, the reserve personnel must be sufficient enough that would not let the patient wait for more than an hour, which means that the preparedness of personnel, service, and correctness. Therefore, it would affect the lessening of mortality rate, increment of lifespan during illness, increment of accessibility, which directly affect the nursing workload particularly outpatient that cause the imbalance between staff and patient [12]. The current problem must be assigned to district health promotion hospital in order to reduce traveling cost and time consumption by the instruction of economic policy from Ministry of Public Health. Looking forward to being standardized, the formal criteria are established equally. By using this method, time consumption and workload are reduced. Also, the cost, intensity, and inequality between local hospital, general hospital, and hospital center are reduced, which will lead to the improvement of quality of life and service [13]. According to the fact that the population in Samut Songkhram has the highest number of elders in Thailand, consists of 18,093 people in total and 2,685 people or $14.84 \%$ in Lad Yai district, the primary target for research field of accessibility and hospitality condition of district health promotion hospital in this location. The expected results will be used as a guideline to future development and management of the service and staff, which would help in being standardized as well as other healthcare institutions.

\section{Objective of the Study}

This research aims to study on the accessibility of elderly to health services in district health promotion hospital, specifically in Lad Yai district, Samut Songkhram for the development of healthcare's procedure.

\section{LITERATURE REVIEW}

\section{Elderly Health Problem}

The main health problems that are found in elderly, according to the report of IHPP, Ministry of Public Health, listed in top five are stroke, coronary artery disease, chronic obstructive pulmonary disease, diabetes, and liver cancer respectively in men and stroke, diabetes, coronary artery disease, Alzheimer's disease, and depression respectively in women. Health promotion program and disease control [14] mention the threat of the hospitality of elders, which is shown in the following list: 
- Caring system and treatment system of elderly is not specifically from other target group of patients, which is the emphasize of disease management rather than case management.

- The standard of elderly treatment in general and local area need the development.

- The treatment needs proper management system and structure.

- The personnel that is intellectual and expert in the field of elderly treatment is needed.

- The service model in the future must support the physically and mentally.

Degeneration treatment of the elders, which also includes the disease prevention. 2\%, and $19 \%$ of elders are bedridden and independence respectively. 58\%, 24\%, 19\%, 4\%, and $3 \%$ of elders are having physical movement, hearing, visibility, learning, and mental control difficulties respectively, and $2 \%$ of them are having unintellectual respond [15].

The health problems in elders are mainly focused on the higher aging states when tissue and organ structure are unavoidably degenerated, but can be diminished and minimize with health management and understanding. The problems are separated into two groups where the first group is the general disease that can occur at any state such as diabetes, heart and liver diseases which has a higher risk when becoming older. Another group is the symptoms that occur only in elders, which are the physical degeneration from aging and debilitating disease.

\section{Changes in Elderly}

The changes when human becomes elders are not only occurred on their physical, but also their mental and social status [16].

\section{Constitutions and Elderly}

Provision of Elder's Rights Protection in National Constitution specify to aid elderly and disables both physically and mentally, encourage and raise their quality of life and selfreliance, as stated in National Constitution 1994, 1997, and 2007.

\section{Diseases and its Statistics in Elders}

According to the research report of National Statistical Office in 2014, the population of elderly in Thailand is over 10 million or $15 \%$ of 65 million in total. Moreover, $3.3 \%$ or more than 0.3 million of elders said that they are healthy, while $16 \%$ or over 1.6 million said that they are worrisome and unhealthy. Including with an additional report from Department of Health in $2013,41 \%, 18 \%, 13 \%$, and $9 \%$ of elderly are having health problems, which are hypertension, diabetes, both respectively, and knee osteoarthritis [17].

\section{Access to Health Services}

The amount of elders who admitted to hospitality at 3 National Primary funds, which are Social Security, Health Insurance, and Government or State Enterprise Officer, is 13\% of the total population in 2009. Therefore, the fact clearly point out that the number of patients is not low at all when compared to the population.

Nowadays, the amount when compared to the population is arranged in small portion. However, the rising number of service providing and fund usage has affected the health service system, and tend to gradually grow. Therefore, the funds are suitably distributed to the usage amount of each hospital [18]. Dr. Sutayut Osornprasop, the expert of World Bank's human development, closed the gap of elderly's accessibility to health services between health impartiality and comprehensiveness. Although all Thai people 
have received Health Insurance fund since 2002, there are elderly who still suffer from the difficulties of accessing the healthcare service. One of the main reason is the incapability of self-reliance and ministration of their relatives, especially over 80 years old and poor which is additionally affected by the lacking of inexpensive public transportation. Therefore, local administration and local village candidates has an important role to aid the elderly healthcare service [19].

\section{District Health Promotion Hospital or Alternatives}

District Health Promotion Hospital has an important role in the healthcare system of Thailand since it is the department that is intimately and expediently to their inhabitants. The main roles are primary care and rehabilitation, which covers the citizen from birth to death including first aid, pregnancy care taking, vaccination, nutrition care, school health, and consumer protection, which also includes abnormalities treatment and rehabilitation from diabetes, hypertension, breast cancer, cervical cancer, care for the disabled and elderly, rehabilitation and other services to the community. The major obstacle in the developing well-standardized and efficient local district hospital is that the quantity of wellqualified personnel is not associated with the number of patients. The problem exists long, and improvement is delayed in action.

\section{Guidelines for the Development of Star District Health Promotion Hospital}

The concept of developing local district hospital to Star district health promotion hospital has the objective to improve the quality by establishing the formal criteria to all district health promotion hospital, which will result in the reduction of intensive usage on local hospital, general hospital, and hospital center. Also, the cost, intensity, and inequality between these hospitals will be reduced.

\section{RESEARCH MODEL}

\section{Population and Sample}

The population group in this research is either over 60 years old male or female that access the service in district health promotion hospital at Lad Yai district, Samut Songkhram. The population size is 477 which is calculated for sample size selection at $15-30 \%$ of population [20] or at least 72 people by using Simple Random Sampling.

\section{Research Methods \& Tools}

The research method is interviewing, which mainly focus on the study of the accessibility to district health promotion hospital at Lad Yai district, Samut Songkhram by using the established standard as the instruction of the interviewing pattern. The questions are separated into two parts. The first part is about general information, which includes gender, age, marital status, graduation, career, personal income, congenital disease from aging, and other comments against service providing. Another part is about the accessibility of the elderly service, which includes staff, service, and tools \& equipment. The opinion is ordered in 3 levels, which are agreeed, uncertain, and disagree. Each part consists of 10 questions, 8 positive questions and 2 negative questions, in total of 40 questions, 32 positive questions, and 8 negative questions.

After collecting the data, the scores from each question are combined to find the average score which is compared to 2, as the mean of all questions [21]. Finally, the result will be translated as shown in the following list: 


\begin{tabular}{lccc}
\hline \hline Positive Question & \multicolumn{3}{c}{ Negative Question } \\
\hline Agree & 3 points & Agree & 1 point \\
Uncertain & 2 points & Uncertain & 2 points \\
Disagree & 1 point & Disagree & 3 points \\
& & & \\
& & & \\
Average Score $>2$ & Treated as Agree & Average Score $>2$ & Treated as Disagree \\
Average Score $<2$ & Treated as Disagree & Average Score $<2$ & Treated as Agree \\
\hline \hline
\end{tabular}

The method is verified by 3 experts by using Index of Item-Objective Congruence or IOC. The given score is equal to 0.8 and confidence level, that is tested with elderly who are not listed in the sample size at the amount of 3,10 , and 30 people, gives 0.7 level of confidence.

\section{The Method for Data Analysis and Translation}

The statistical analysis method is Descriptive Statistics that extracts from frequency, percentage, average mean, and standard deviation.

\section{DATA ANALYSIS}

The results from the study found out that $73.6 \%$ were women as shown in Table 1, 29.2\% were between $75-79$ years old as shown in Table 2, 48.6\% were married, $63.9 \%$ were graduated at primary degree, and $66.7 \%$ were unemployed, and $65.0 \%$ had a lower salary than 5,000 baht. I addition, $18.1 \%, 16.7 \%$, and $9.7 \%$ have only hypertension, hypertension \& diabetes, and hypertension \& heart disease respectively as shown in Table 3. Furthermore, this research found that the opinions against the accessibility to overall healthcare at high levels $(\bar{X}=2.89, S . D=0.10)$, service location was appropriate lighting and personnel in highest levels $(\bar{X}=3.00, S . D=0.00)$, personnel found that understand the mean scores were at the highest level $(\bar{X}=3.00, S . D=0.00)$ whish was resulted from the staff said verbally polite, the staff expressions annoyed when asked, the staff was attentive and enthusiastic about the service, the staff willing to assist you, staff advised the relatives of elderly health care and description of the staff was easy to understand as shown in Table 4. Finally, the tools and equipment were given in high levels $(\bar{X}=2.99, S . D=0.12)$ which was resulted from the tools and equipment were up-to-date, while proper procedures also offer in highest levels $(\bar{X}=3.00, S . D=0.00)$.

TABLE 1 . The amount and percentage of elderly's gender in sample group $(n=72)$

\begin{tabular}{lcc}
\multicolumn{3}{c}{$(n=72)$} \\
\hline Gender & $(\boldsymbol{n}=\mathbf{7 2})$ & Percentage \\
\hline 1. Male & 19 & 26.4 \\
2. Female & 53 & 73.6 \\
Total & 72 & 100.0 \\
\hline \hline
\end{tabular}

The overall opinion against the service accessibility found that 2.97, personnel, provides the best score, follow up with 2.91, tools \& equipment.

According to the opinion of 72 samples, most of elders felt that the service provide good procedure and correctness, which gave average score of 3.00, the highest score. The second highest score was 2.99 , low quality service and hardly cure. Finally, the lowest 
TABLE 2 . The amount and percentage of elderly age in

\begin{tabular}{lcc}
\multicolumn{3}{c}{ sample group $(n=72)$} \\
\hline \hline Age (years) & $(\boldsymbol{n}=\mathbf{7 2})$ & Percentage \\
\hline 1. 60 - 64 years old & 10 & 13.9 \\
2. 65 - 69 years old & 12 & 16.7 \\
3. 70 - 74 years old & 19 & 26.4 \\
4. 75 - 79 years old & 21 & 29.2 \\
5. 80 - 89 years old & 10 & 13.9 \\
6. More than 90 years old & 1 & 1.4 \\
Total & 72 & 100.0 \\
\hline \hline
\end{tabular}

TABLE 3 . The amount and percentage of congenital disease in elderly ( $n=72)$

\begin{tabular}{lcc}
\hline \hline Congenital Diseases & $(\boldsymbol{n}=\mathbf{7 2})$ & Percentage \\
\hline 1. Healthy & 11 & 15.3 \\
2. Diabetes & 5 & 8.3 \\
3. Heart Disease & 4 & 5.6 \\
4. Kidney Disease & 2 & 2.8 \\
5. Hypertension & 13 & 18.1 \\
6. Dyslipidemia & 2 & 2.8 \\
7. Rheumatoid arthritis & 1 & 1.4 \\
8. Diabetes and Hypertension & 12 & 16.7 \\
9. Diabetes and Dyslipidemia & 2 & 2.8 \\
10. Hypertension and Gout & 1 & 1.4 \\
11. Diabetes, Hypertension and Dyslipidemia & 2 & 2.8 \\
12. Heart Disease, Hypertension and Dyslipidemia & 1 & 1.4 \\
13. Kidney Disease, Hypertension and Dyslipidemia & 1 & 1.4 \\
14. Heart Disease and Hypertension & 7 & 9.7 \\
15. Diabetes, Kidney Disease, and Hypertension & 1 & 1.4 \\
16. Diabetes and Heart Disease & 1 & 1.4 \\
17. Diabetes and Gout & 1 & 1.4 \\
18. Hypertension and Dyslipidemia & 4 & 5.6 \\
Total & 72 & 100.0 \\
\hline \hline
\end{tabular}

TABLE 4. The mean, standard deviation, and opinion against the healthcare accessibility of elderly $(n=72)$

Healthcare Accessibility $\quad$ Mean $\bar{X} \quad$ Standard Deviation (S.D) $\quad$ Translated Opinion

\begin{tabular}{llll}
\hline 1. Service Location & 2.85 & 0.22 & Likely Agree \\
2. Personnel & 2.97 & 0.08 & Likely Agree \\
3. Tools \& Equipment & 2.91 & 0.13 & Likely Agree \\
4. Service Quality & 2.84 & 0.15 & Likely Agree \\
Total & 2.89 & 0.10 & Likely Agree \\
\hline \hline
\end{tabular}

score at 2.47 was the long waiting queue and process before having a service provided. The tested result was shown the following Table 5 . 
TABLE 5. The mean, standard deviation, and opinion against the service accessibility of elderly $(n=72)$

\begin{tabular}{lccc}
\hline \hline Service Accessibility & Mean $(\bar{X})$ & Standard Deviation $(S . D)$ & Translated Opinion \\
\hline 1. Service provides good procedure and Correctness & 3.00 & 0.00 & Likely Agree \\
2. Provide free beverage & 2.88 & 0.41 & Likely Agree \\
3. Staff provides knowledge and demonstrate hand washing & 2.92 & 0.40 & Likely Agree \\
4. Provide good quality service & 2.67 & 0.75 & Likely Agree \\
5. Low quality service and hardly cure & 2.99 & 0.12 & Likely Agree \\
6. Long waiting queue and process before having a service provided & 2.47 & 0.71 & Likely Agree \\
7. Correctness of receiving medicine after medical check & 2.94 & 0.33 & Likely Agree \\
8. Proper queuing process from case control & 2.90 & 0.30 & Likely Agree \\
9. Local and public telephone call number are presented & 2.83 & 0.38 & Likely Agree \\
10. Witness the comment boxes and notice the feedback from the comments & 2.81 & 0.49 & Likely Agree \\
Total & 2.84 & 0.15 & Likely Agree \\
\hline \hline
\end{tabular}

\section{DISCUSSION}

As a result from this research found out that the sample group that received the service from district health promotion hospital at Lad Yai district, Samut Sakhon, had positive opinion against healthcare service and accessibility $(\bar{X}=2.89, S . D=0.10)$ which was ordered in the following list:

\section{Service Location}

This research found out that elderly has the highest positive opinion against appropriate lighting and ventilation $(\bar{X}=3.00, S . D=0.00)$ while the highest negative opinion of low amount of medical checking room and hot \& stuffy environment $(\bar{X}=2.58, S . D=0.71)$, so the suggestion to this improvement was increasing medical checking room and controlling the room temperature

\section{Personnel}

This research found out that elderly had the highest positive opinion against politely, attentive, rarely instruct, and easy to understand while discussing with the staff $(\bar{X}=3.00$, $S . D=0.00$ ) while the highest negative opinion was the staff showed the sign of feeling annoyed $(\bar{X}=3.00, S . D=0.00)$ which needed greatly improvement. In addition, the least positive opinion was the frequent house visiting rate $(\bar{X}=2.86, S . D=0.39)$, which also needed a little bit of improvement.

\section{Tools \& Equipment}

This research found out that the elderly had highest positive opinion against the modernized tools and equipment $(\bar{X}=2.99, S . D=0.12)$ while the highest negative opinion was ineffectiveness of tools to the patient's health $(\bar{X}=2.63, S . D=0.76)$, so the suggestion to this improvement was to demonstrate the importance and efficiency of the tools \& equipment to their health.

\section{Service Quality}

This research found out that the elderly had highest positive opinion against the correctness $(\bar{X}=3.00, S . D=0.00)$ and the highest negative opinion was the long waiting $(\bar{X}=$ $2.47, S . D=0.71$ ), so, as being stated in the research result of Tanucha Tunwong, 2016, the suggestion to this improvement was to reduce the patient's waiting time. Also, it was 
found that the hospital had to have preparedness on service location, cleanness, patient reserves, efficient tools \& equipment, well-qualified personnel, and the confidence of service providing, so that the patient could trust and accept the service.

\section{CONCLUSION}

According to the result, it is concluded that the opinion against the accessibility of district health promotion hospital at Lad Yai district, Samut Songkhram, likely agrees, which follows the assumptions. However, there are several points that need improvements, particularly the lowest average score of low reserve medical checking room and hot \& stuffy environment, which need to be handle in order to prevent the risk of fainting or any possible risk of severe illness condition, frequent house visiting rate, which provides the tracing of the patient's health status and properly instruct the risk to other feasible disease, annoying sign of the staff, and the waiting time that can be settled by several ways such as additionally arrange for elderly patient since this patient group is considered to be the group of having health risk.

\section{ACKNOWLEDGMENT}

The researcher would like to thank the elderly and staffs in Tambon Ban Khetmuang District Health Promotion Hospital, Tambon Lat Yai, Samut Songkhram Province. . This research was supported by Suan Sunandha Rajabhat University, the researcher would like to thank College of Allied Health Sciences, SamutSongkhram Education Center for supporting this achievement.

\section{REFERENCES}

1. Pramote, Prasartkul. Thai elderly situation; 2015. Available from: https://bit.ly/2BT98Rr

2. Fahmida MSU, Kulsuma BM, Reza AAT. Energy balance and its relationship with metabolic disease in Bangladeshi middleaged women. Journal of Advances in Health and Medical Sciences. 2016; 2(2): 61-69.

DOI: https://doi.org/10.20474/jahms-2.2.3

3. Kharismadhany UE, Sari, Rakhmah QA. Increasing women's awareness on the importance of early detection of cervical cancer through socialization method and focus group discussion in Sabdodadi village Bantul, Yogyakarta. Journal of Advances in Health and Medical Sciences. 2017; 3(1): 9-16. DOI: https://doi.org/10.20474/jahms3.1.2

4. Thilakarathna, M. Issues encountered in community health in Sri Lanka with special reference to Polpithigama rural village in North-Western province. Journal of Advances in Health and Medical Sciences. 2017; 3(3): 96-105.

DOI: https://doi.org/10.20474/jahms3.3.1

5. Office of the National Economic and Social Development. The national economic and social development plan; 2017. Available from: https://bit.ly/2wFn7J0

6. Prabsangob, K. Relationships of health literacy diabetes knowledge and social support to self-care behavior among type 2 diabetic patients. International Journal of Health and Medical Sciences. 2016; 2(3); 68-72.

DOI: https://doi.org/10.20469/ijhms.2.30005-3

7. Rachawong C, Juntongjin P. Public knowledge towards Vitiligo. International Journal of Health and Medical Sciences. 2017; 3(2): 38-42. DOI: https://doi.org/10.20469/ijhms.3.30002-2

8. International Human Rights Clinic. The protection of the elderly model law; 2012. Available from: https://bit.ly/2Ef6qbe

9. Sindin AI. Is total quality management/continous quality improvement or quality assurance applicable in health services. International Journal of Health and Medical Sciences. 2016; 2(1): 7-12.

DOI: https://doi.org/10.20469/ijhms.2.30002-1 
10. Kittichottipanich B, Yingpaiboonsook U, Somsauy P, Kositwon S. Model of health promotion for reducing risky behaviors of preterm birth in teenage pregnancy. International Journal of Health and Medical Sciences. 2016; 2( 1): 20-26. DOI: https://doi.org/10.20469/ijhms.2.30004-1

11. Juliansyah E, Asnol UB. Workers behavior in maintaining health management waste in the final disposal. International Journal of Health and Medical Sciences. 2016; 2(2): 32-36. DOI: https://doi.org/10.20469/ijhms.2.30002-2

12. National Health Security Office. Information on public health services; 2013. Available from: https://bit.ly/2SvqFo2

13. Sriprasert Pisit, Boonsrimanichai Manu. Standards for health promotion in Hospitals; 2016. Available from: https://bit.ly/2AU4dOp

14. Ministry of Public Health. Major health problems of the elderly; 2014. Available from: https://bit.ly/2APxiKI

15. Tiantong, Anusun. Threatening the care of the elderly today; 2016. Available from: https://bit.ly/2Qz25p6

16. Senachai, Ari. Changes in the elderly; 2013. Available from: https://bit.ly/2zJp1YT

17. Bangkok Business Media. Disease statistics of the elderly; 2014. Available from: https://bit.ly/2fFmjaz

18. Thailath Press Release Local. Close the gap to access the elderly's health services; 2016. Available from: https://bit.ly/2zJr0we

19. Maharuenkhwan, Panubetd. Thailand fund. Economy Newspaper. 2010; 38(3): 3-8.

20. Srisaad, Boonchom. Recipes or Estimates of Population Use Sample Size 15-30\%; 1992. Available from: https://yhoo.it/2QyWQWl

21. Panita Pongsawet. Access to healthcare services for the elderly Damnoen Saduak District Ratchaburi Province. 2008. Unpublished master thesis, Silpakorn University, Bangkok, Thiland.

— This article does not have any appendix. - 